\title{
Consumer health information
}

\author{
Compiled by Susan Murray
}

\section{MedlinePlus}

Starting in December 2006, there are weekly updates by Dr. Donald Lindberg, Director of the National Library of Medicine (NLM), highlighting new materials on MedlinePlus. You can subscribe to the updates that are available in both audio and text. You can also access PDF copies or sign up to receive issues of NIH MedlinePlus Magazine, a quarterly guide for patients and their families (see http://www.nlm.nih.gov/medlineplus/magazine.html).

\section{Health literacy: recent articles}

J Gen Intern Med. 2006;21:803-900. Special issue on health literacy. Of special interest - Brief report: Screening items to identify patients with limited health literacy skills. LS Wallace et al., pp. 874-7.

Norman CD, Skinner HA. eHealth literacy: essential skills for consumer health in a networked world. J Med Internet Res. 2006;8(2):e9. Available from http://www.jmir.org/ 2006/2/e9/.

Norman CD, Skinner HA. eHEALS: the eHealth literacy scale. J Med Internet Res. 2006;8(4):27. Available from http://www.jmir.org/2006/4/e27/.

Olney CA, Warner DG, Reyna G, Wood FB, Siegel ER. MedlinePlus and the challenge of low health literacy: findings from the Colonias project. J Med Libr Assoc. 2007;95(1):31-9. Available from http://www. pubmedcentral.nih.gov/articlerender.fcgi?artid= 1773027 .

Rootman I. Health literacy: where are the Canadian doctors? CMAJ. 2006;175(6):605-6.

Sostack M. The hidden shame of adults with low health literacy issues. MLA News. 2007 January;1,12.

\section{Notable new publications and Web sites}

Fundamentals of Complementary and Integrative Medicine. 3rd ed. By Marc S. Micozzi. St. Louis, Mo.: Saunders Elsevier, 2006. CAN\$85.95. ISBN-13 978-1-4160-2583-2.

In his introduction, Dr. C. Everett Koop (former US Surgeon General) points out that $80 \%$ of the world's population depends on alternative health approaches, and one-third of
American adults regularly use some form of complementary and alternative medicine (CAM) (in Canada, it is one-fifth of adults). This is the text used in medical schools and provides a good overview of the major CAM therapies and modalities, as well as what scientific evidence exists.

Therapeutic Nutrition: A Guide to Patient Education. By Eileen Behan. Philadelphia: Lippincott Williams \& Wilkins, 2006. CAN\$61.50. ISBN 1-58255-380-7.

Authored by a nutritionist, this book provides 135 patient handouts for diet choices, including handouts on various allergies and health conditions, extensive information on vitamins and supplements, suggestions for weight control and obesity treatment and prevention, and the calorie content of selected foods and fast foods.

The Extraordinary Healing Power of Ordinary Things: Fourteen Natural Steps to Health and Happiness. By Larry Dossey. New York: Harmony Books, 2006. CAN\$34.95. ISBN 0-307-20989-X.

Dr. Larry Dossey, one of the founders of mind-body medicine, discusses and explores the research for the simple sources of healing, such as optimism, music, plants, dirt, and doing nothing.

\section{Insidermedicine}

http://www.insidermedicine.ca

When CBC National News contacted CHIS in December about a story they were doing on consumers looking for health information on the Internet, we became aware of Insidermedicine. This online video health news site, developed and maintained by Drs. Sanjay and Susan Sharma, features a series of 1-3 min videocasts. News can be searched by disease, category, or keyword.

\section{People Living With Cancer}

\section{http://www.plwc.org/portal/site/PLWC}

This patient information Web site of the American Society of Clinical Oncology was redesigned in 2006 to be more user-friendly. It includes a range of consumer resources, including comprehensive guides to more than 120 types of cancer and cancer-related syndromes. 


\section{Caring Voices}

\section{http://www.caringvoices.ca/en/}

Caring Voices, an online community for breast cancer survivors, is an initiative of the Princess Margaret Hospital. It includes a resource library, events section, chat \& forums section, and a people section that lets users build up a community of friends to turn to for advice and support.

\section{Health Canada: Medical use of marihuana}

http://www.hc-sc.gc.ca/dhp-mps/marihuana/index_e.html

Tucked in the drugs and health products section of the Health Canada site, is information about applying for medical use of marihuana. Did you know if you are authorized by Health Canada to possess dried marihuana for medical purposes, you can apply for a Personal-Use Production Licence (see http://www.hc-sc.gc.ca/dhp-mps/marihuana/ how-comment/index_e.html)?

\section{Holistic Health Research Foundation of Canada}

http://www.holistichealthresearch.ca/publicawareness.php

The Holistic Health Research Foundation of Canada is a national charitable organization dedicated to supporting multidisciplinary research, public awareness, and professional education in complementary and alternative health care. They are producing evidence-based information resources for the public and health professionals; just posted is an introductory booklet describing various complementary therapies, the philosophy behind them, and listings of Canadian associations for further information.

\section{Complementary and alternative health: statistics and readings}

\section{Definition of CAH}

Complementary and alternative health care (CAHC) covers a broad range of therapies and healing practices. Acupuncture, chiropractic, and naturopathy are some of the most familiar forms of CAHC, but prayer and taking vitamins can also be considered complementary health care. There are many other terms for CAHC, such as complementary and alternative medicine (CAM), alternative medicine, holistic health, and integrative medicine [1].

\section{Utilization of CAH}

Since the mid 1990s, when CAH utilization statistics for Canadians began to be compiled, a steadily increasing trend of usage has been documented. Cross-comparisons of these statistics are difficult, as researchers include different therapies in their surveys. Other surveys focus only on use of natural health products (NHPs). The 2005 Canadian Community Health Survey indicates the most frequently consulted CAH practitioners are chiropractors, massage therapists, and acupuncturists.
The sampling of statistics below reflects the demographics of CAH use, as well as some of the reasons Canadians are drawn to this field of health care.

(i) In 2003, one-fifth of Canadians aged 12 or older, or an estimated 5.4 million people, reported having used some type of alternative or complementary health care.

(ii) An estimated $11 \%$ of the population aged 12 or older has consulted a chiropractor (the most common form of alternative care). Around $8 \%$ have consulted a massage therapist, $2 \%$ an acupuncturist, and $2 \%$ a homeopath or naturopath.

(iii) Women are more likely than men to have sought a $\mathrm{CAH}$ consultation. Mid-life Canadians are the most likely to use CAHC, while the very young and seniors are less likely to have used it. CAH use has traditionally been higher in the western provinces than in other parts of the country.

(iv) Around one-quarter (26\%) of individuals in the highest household income group had used alternative care in 2003. In contrast, only $13 \%$ of those in the lowest income group had done so. Cost is considered an entrenched barrier to CAHC access.

(v) $\mathrm{CAH}$ use tends to rise with level of education. More than one-quarter of postsecondary graduates used some kind of alternative or complementary health care in 2003 , compared with $16 \%$ of people with less than secondary school graduation.

(vi) Chronic health conditions also contribute to interest in CAHC. About one-quarter of people who reported having at least one diagnosed chronic condition (such as fibromyalgia and back problems) reported consulting an alternative practitioner in 2003. This contrasts with $16 \%$ of people who did not report any chronic conditions.

(vii) People with chronic and terminal diseases such as cancer are also intensive users of complementary therapies, using them for symptom management and improved quality of life [2,3].

Natural health products: vitamins, minerals, herbal medicines, homeopathy, and other supplements

- Regulations about NHPs in Canada came into force on 1 January 2004 and apply to all NHPs as of this date. For more information, see About Natural Health Product Regulation in Canada at http://www.hc-sc.gc.ca/dhp-mps/ prodnatur/about-apropos/index_e.html.

- The 2003 Canadian Community Health Survey reported that $20 \%$ of Canadians aged 12 or older said they had visited a natural health practitioner — mostly chiropractors, massage therapists, and acupuncturists.

- The Natural Health Products Directorate's 2005 survey of Canadians aged 18 and over showed that $71 \%$ of the people who answered regularly use NHPs, taking vitamins, herbal products and homeopathic medicines as well as other supplements. Seventy-seven percent said they use natural health products to maintain and promote health, and $68 \%$ said they use NHPs to treat illness $[6,7]$. 


\section{Communicating with health care providers about the use of CAH}

Typically, Canadians do not inform their doctors about their use of complementary and alternative therapies. They report that negative physician response, feeling the physician did not need to know about $\mathrm{CAH}$ use, or not being asked are their primary reasons for not disclosing. This can increase risks. "This practice results in the fragmentation of health care, which ideally should be coordinated" [4].

\section{Health insurance coverage for $\mathrm{CAH}$}

- Health insurance coverage for alternative therapies is not consistent across Canada.

- There is no coverage for chiropractic in provinces east of Ontario or in the Yukon or Northwest Territories. Naturopathic medicine is partially covered only in British Columbia.

- Coverage by workers compensation boards is also uneven across the country [4].

\section{Spending on CAH}

- Canadians are spending \$3.8 billion a year on CAH [2].

For more information, visit the Complementary and Alternative Health section of the Canadian Health Network (www.canadian-health-network.ca). From Topics on the left side, select Complementary and Alternative Health.

\section{References}

1. Canadian Health Network [Web page]. Complementary and Alternative Health section, FAQs. Available from www.canadian-health-network.ca.

2. Ramsay C, Walker M, Alexander J. Alternative medicine in Canada: use and public attitudes. Public Policy Sources, Number 21. Toronto: The Fraser Institute, 1999. Available from http://oldfraser.lexi.net/publications/pps/21/.
3. Eng JL, Monkman DA, Verhoef MJ, Ramsum DL, Bradbury J. Canadian Cancer Society Information Services: lessons learned about complementary medicine information needs. Chronic Diseases in Canada. 2001;22(3/4). Available from http://www.phac-aspc.gc.ca/publicat/cdic-mcc/22-3/d_e.html.

4. Complementary and alternative health practices and therapies: a Canadian overview. Toronto: York University Centre for Health Studies, 1999. Available from http://www. yorku.ca/ychs/Compl_Altern_Health.pdf.

5. de Bruyn T. A summary of national data on complementary and alternative health care - current status and future development: a discussion paper. Prepared for Health Canada, 2002. Available from http://www.hc-sc.gc.ca/dhp-mps/pubs/ complement/cahc-acps-summary-synthese/cahc-acps-summarysynthese_1_e.html.

6. Health Canada. Baseline natural health products survey among consumers. March 2005. Natural Health Products Directorate. Available from http://www.hc-sc.gc.ca/dhp-mps/pubs/natur/ eng_cons_survey_e.html.

7. Health Canada. About natural health product regulation in Canada. Available from http://www.hc-sc.gc.ca/dhp-mps/ prodnatur/about-apropos/index_e.html.

8. McKenzie P, Oliphant T. The presentation of complementary and alternative medicine information in Canadian midwifery care. Available from http://www.cais-acsi.ca/proceedings/ 2006/mckenzie_2006.pdf.

9. PasseportSanté.net Utilisation des MAC : l'OMS suggère des normes. http://www.passeportsante.net/fr/Actualites/Nouvelles/ Fiche.aspx?doc $=200406250$.

10. Public Health Agency of Canada. Perspectives on complementary and alternative health care, a collection of papers prepared for Health Canada. 2001. Available from http://www. phac-aspc.gc.ca/publicat/pcahc-pacps/index.html.

11. Park J. Use of alternative health care. Health Reports. 2005 March; 16(2). Available from http://www.statcan.ca/english/ ads/82-003-XPE/pdf/16-2-04.pdf or http://www.statcan.ca/ francais/freepub/82-003-XIF/0020482-003-XIF.pdf. 